\title{
QUESTÕES SOBRE IDENTIDADE E DIFERENÇA: TENSÃO ENTRE O MESMO E O OUTRO
}

\author{
Vera Lúcia Pires \\ GRPESQ/CNPq Discurso, História, Gênero e Identidade
}

No início dos anos 70, na Europa e EUA, surgiu um novo conceito: política da identidade, tendo como características principais dois pontos: primeiro, a ênfase nas questões de diferenças em detrimento das questões de igualdade e universalidade; e como reflexo da primeira, ênfase a comunidades de identidades particulares como afros, hispânicos, gays, ou lésbicas. Assim, tendo em vista a lógica da dominação que hegemonizara uma identidade: branca, masculina, ocidental, heterossexual, etno e androcêntrica, procurou-se recuperar o pólo desvalorizado das dicotomias.

Em filosofia, de onde o termo é originário, identidade refere-se primeiramente, aquilo que dá a alguém sua natureza essencial e sua continuidade; em seguida, ao que faz duas pessoas, ou grupos de pessoas, terem características comuns. O conceito envolve negação e diferença: algo é alguma coisa e não outra. Por tal motivo, é comum se ouvir falar de políticas de identidade ou de filosofias da diferença para abordar o mesmo assunto, qual seja, grosso modo e amplamente, o direito das pessoas expressarem livremente o seu pensamento e serem o que quiserem ser.

Se o tema teve uma maior visibilidade após os acontecimentos de 68, entretanto, ao longo do século $\mathrm{XX}$ ele contabilizou diversas expressões, todas elas ligadas, de alguma forma, à crítica marxista ou à crítica psicanalista. A crítica marxista defendia a universalidade do ser humano, determinado socialmente por divisões de classe. Já a psicanalista refletia a separação do indivíduo das determinações sociais ou, dito de outro modo, postulava a existência de um ser subjacente, à parte, dentro de todos nós - uma identidade inconsciente. A antinomia 
público/privado estava no âmago desse conflito, como veremos adiante.

O postulado freudiano da estrutura edipiana do inconsciente, ligando a posição de cada sexo e sua diferenciação à sua configuração morfológica, definira o feminino negativamente em relação ao masculino e pregara a inferioridade feminina em razão da falta do órgão viril, do qual a mulher teria inveja. Como contraponto a esta valorização do caráter transcultural e a-histórico do modelo edipiano da formação das diferenças entre os sexos, desenvolveuse inicialmente, na própria área psicanalítica, um pensamento que atribuía aos aspectos sócio-culturais as diferenças de gênero.

Tal referência impulsionou o pensamento crítico feminista, fazendo Beauvoir $\left(1949^{1}\right)$ afirmar que o segundo sexo seria acima de tudo uma construção social, uma metáfora da alteridade, ou seja, o conceito mulher seria construído culturalmente como o outro, baseado em um paradigma identitário masculino.

A força mais importante na redefinição da questão da identidade, segundo Zaretsky (1994), foi indubitavelmente a emergência e consolidação do movimento de liberação das mulheres, por dois motivos, a saber: o movimento constituiu-se parte de uma luta contínua pela igualdade e conseguiu uma conquista histórica ao desnudar a natureza social da família, ou seja, a natureza pública do que sempre fora considerado privado, com base nas conexões internas entre a família e a economia.

Esboçaremos, a seguir, algumas considerações sobre a história das teorias de gênero nas últimas décadas e sua contribuição para o desenvolvimento do assunto em pauta.

\section{ALGUMAS PALAVRAS SOBRE AS TEORIAS DE GÊNERO}

A década de setenta inaugurou novos estudos e contestações no campo feminista. Na França, na esteira de maio de 68 , as feministas postularam que a discriminação sexual dava-se por meio de uma violência simbólica que silenciaria a voz das mulheres, excluindo-as de produzir. De propor e decidir. A partir de então, posicionaram-se contra o termo feminista e propuseram 
feminino como metáfora da alteridade. A questão da diferença passou a ser um conceito cultural de construção da linguagem.

O movimento francês dividiu-se, na metade dos anos 70 , entre as seguidoras de tendências marxistas e as comprometidas com o pensamento psicanalítico lacaniano e pós-estruturalista. As primeiras advogaram o primado do determinismo econômico nas questões relativas às diferenças entre os sexos e contestaram a dominação invocada pela natureza sexual, pois essa seria o cerne da desigualdade. Na sua opinião, a luta maior, pela emancipação coletiva dos seres humanos, seria representada pela abolição da opressão ligada às classes sociais. Já a tendência psicanalítica, preocupada com os processos de formação de uma identidade subjetiva de gênero por meio da linguagem, privilegiou a discussão e análise dos discursos e textos femininos, propondo a existência de uma escritura feminina que subverteria o padrão masculino de expressão. Ambas as correntes enfatizaram uma estrutura universal de construção da identidade feminina em detrimento das questões específicas. Entretanto, a primeira foi denominada de feminismo da igualdade, enquanto a essa propos-se a alcunha de feminismo da diferença.

Não obstante, nesse mesmo período, influenciada pela tendência marxista do feminismo francês, Rubin (1975) teorizou sobre a opressão em termos de uma economia política de relações de trabalho, usando pela primeira vez o termo gênero em relação a condutas construídas socio-culturalmente e que enfatizariam as relações de poder de um sexo sobre o outro com base nas diferenças biológicas. Tais diferenças, transpostas para a divisão sexual do trabalho, instituiriam esferas femininas privadas e masculinas públicas. Para o discurso feminista anglo-americano, o termo gênero caracterizava um significado social, cultural e psicológico imposto pela identidade sexual biológica.

Conforme de Certeau (1974), os movimentos contestatórios são, em seus primeiros momentos, movimentos de negação: contradizem o instituído, o senso comum e alguns valores sócioculturais. A negação do outro thes permite um gesto de identificação. Há sempre um desejo de querer existir, uma vontade de autonomia, que emerge da tomada de consciência da opressão. Seu objetivo será, então, quebrar o círculo do cultural. Para que tal 
aconteça, é preciso conquistar a palavra, encontrar um lugar onde seja possível situar-se e ter a capacidade de exprimir-se, ter enfim uma representação cultural que estruture os significados e dê forma às experiências vividas.

Para além das tendências, os feminismos dos anos 60 e 70 conquistaram a palavra e desempenharam um papel fundamental, inscrevendo o feminino como uma categoria essencial para uma política de identificação cultural. O crescimento dos movimentos de liberação das mulheres na Europa e nas Américas, integrando os movimentos de reivindicação social em sua luta contínua por igualdade, cidadania e emancipação, coincidiu com a expansão da mão de obra feminina na economia pós-industrial e começou a modificar o panorama ocidental das relações sociais de gênero. Nesse sentido,

... as correntes feministas colocaram o problema do acesso das mulheres à posição de sujeito: sujeito político e sujeito crítico a um saber científico. Inscrição de um pensamento utópico que se quer sujeito político e sujeito enunciador da palavra (Machado, 1997: 102).

A partir do começo dos anos 80 , as teorias críticas feministas viram o tema gênero desenvolver-se no campo das ciências humanas e sociais, referindo-se ao estudo das relações de gênero que envolvem mulheres e homens ${ }^{2}$. Opondo-se às teorias anteriores que se centravam nas questões específicas e na experiência feminina, essas pesquisas deveriam, mais que estudar mulheres, integrar o estudo das diferenças, todas elas: de gênero, de raça e de classe nas ciências sociais e, indo adiante, investigar a forma como essas diferenças são conduzidas com o intuito de manter ou transformar a ordem social.

O apelo à construção de identidades, calcado na ênfase das diferenças de gênero (inclusas todas as orientações sexuais), raça (com todas as etnias) e classe social, mobilizou o debate teórico nas ciências sociais. As minorias marginalizadas e silenciadas reclamaram e lutaram por um espaço próprio que as iluminasse. Contribuíram, igualmente, para deslocar a perspectiva 
teórica da análise das diferenças tanto das questões exclusivas relacionadas às mulheres quanto da universalidade biológica anterior às representações e práticas sociais.

Nem o feminismo nem a representação do feminino são valores universais (Duby \& Perrot, 1993: 15). Ser mulher no ocidente não tem o mesmo significado que o ser no oriente. Por isso a construção da identidade feminina se dá sob o signo da pluralidade: não mais a mulher, mas mulheres, diferentes na sua condição social, em suas crenças, na etnia, no seu itinerário individual, mas certamente com algumas experiências em comum. A busca da identidade e reconhecimento de si mesmo é também a consciência de nossas diferenças. É, ao mesmo tempo e contraditoriamente, uma aproximação e uma distinção dos outros.

\section{DA CONTRADIÇÃO COMO PRINCÍPIO FUNDADOR DA IDENTIDADE E DA DIFERENÇA}

A fim de recuperarmos as bases do problema da identidade e da diferença, é conveniente lançarmos os olhos sobre os ensinamentos da filosofia moderna, que nos diz ser o pensamento relacional o fundamento do conhecimento. As visões idealistas estabilizavam os objetos da realidade a conhecer e seu conhecimento era dado através da idéia e da criação de um conceito a seu respeito. A experiência era negada e o objeto em si tornava-se estranho ao sujeito, que dele recebia uma idéia pré-concebida.

O pensamento materialista, ao contrário, sempre partiu da experiência real com os objetos. O primeiro movimento é o reconhecimento identificador do objeto pelo estabelecimento de relações de identidade com outros objetos já sabidos. A partir de então, avança-se em direção às diferenças que levarão à construção de novos conhecimentos. Para a visão materialista, o conhecimento é construído a partir da experiência real, aceitando-se as contradições que nela existem.

A ciência filosófica do materialismo dialético tornou a categoria da contradição um dos princípios fundamentais de sua análise da realidade. No desenvolvimento social, existem elementos opostos no processo de evolução. Tais elementos, os contrários, 
apesar de possuírem aspectos radicalmente diferentes, são imprescindíveis um ao outro, pois há em cada um deles alguma coisa essencial que o outro não possui. Eles interpenetram-se pela existência de alguma identidade e afastam-se porque um elemento nega e exclui alguma coisa do outro. Essa relação de interação e tensão é permanente e constitui o que se convencionou chamar de contradição ou unidade e luta dos contrários. Nem sempre os contrários manifestam-se claramente e as visões imediatistas raramente conseguem distingui-los. Eles estão, entretanto, na base de toda a transformação da realidade, provando a importância da identidade e da diferença.

Desde que se colocou em dúvida a tradição cartesiana da filosofia da consciência, o sujeito viu-se na contingência de encarar o outro. A identidade de um ser não está nele mesmo, mas naquele ser ao qual se opõe (Chauí, 1983: 225). A filosofia humanista clássica, tomando como referencial a interioridade do homem, ou seja, a subjetividade individual, caracterizara 0 sujeito de consciência pela capacidade de produzir a partir de si mesmo, de suas idéias e de seus estados interiores, o sentido do real. Sentido esse marcado pela transparência e pela identidade. Nesse caso, considerava-se a contradição como sinônimo de irreal. Foi pela via da dialética, posteriormente, que se estabeleceu a negação do sujeito pleno e do sentido literal.

Descombes (1979) afirmou que o universo exterior impugna a consciência subjetiva, tornando-Ihe a identidade precária. Como conseqüência, o outro exterior põe em perigo o mesmo, fazendo com que a consciência adquira um novo estatuto: o ser de consciência é agora concebido como um ser dialético que, em relação tensa e de conflito com o mundo, expressa a negação do idêntico. A negação torna-se a própria diferença. Atente-se, no entanto, que a negação dialética não destrói as coisas em si, senão o seu sentido imediato, superando-o e propondo um novo sentido.

Atuar na natureza é trabalhar para não ser tal como somos. (Descombes, ibid.: 60). Por isso, o ser humano seria capaz de atuar para transformar, de criar condições para o advento do novo, mudando assim o curso das coisas e da história. Esse ser dialético seria um sujeito ator, histórico e não-natural, pois, em tensão com a realidade, negar-se-ia a deixar certas coisas seguirem 
seu curso ao acaso, permanecendo sempre iguais, como se negaria também a reproduzir um conhecimento espontâneo e imediato que servisse somente para formar a alienação e o senso comum.

Após esse breve comentário sobre como a categoria da contradição funda o tópico das relações entre identidade e diferença, prosseguiremos verificando a questão no âmbito dos estudos lingüísticos.

\section{A TENSÃO ENTRE O MESMO E O OUTRO DO PONTO DE VISTA DA LINGUAGEM}

Em sua produção lingüística, da mesma forma que em sua relação com os outros e com o mundo, o sujeito manifesta a contradição. Este é um tema predominante na obra de Bakhtin, para quem a tensão dialética seria uma das características principais do signo lingüístico. Nele habitariam, concomitantemente, traços de valor contraditórios que produziriam sentidos diversos, mesmo antagônicos, por refletirem não passivamente, mas de maneira polêmica, o sujeito e seu horizonte social. Ao produzir um enunciado, o sujeito posicionar-se-ia em relação a já-ditos-outros que, pela via da história, teriam uma continuidade semântica. Mesmo que a seqüência linear do enunciado fosse a mesma, tendo em vista que é um outro momento da história, o enunciado significaria diferente.

A linguagem, para Bakhtin, era vista como uma prática social cotidiana a envolver a experiência do relacionamento entre sujeitos. Essa experiência seria parte integrante do sentido do dizer. A realidade material da linguagem seria, para o autor, a língua, entendida não como um sistema abstrato de formas lingüísticas à parte da atividade do falante, mas como um processo de evolução ininterrupto, constituído pelo fenômeno social da interação verbal, realizada através da enunciação, que seria a sua verdadeira substância (Bakhtin, 1929: 127). Defendendo a natureza social e não individual da linguagem, ele situou a sua realidade material língua -, bem como aos indivíduos que a usavam, em um contexto sócio-histórico. A língua penetra na vida através dos enunciados concretos que a realizam (Bakhtin, 1979²: 282), da mesma forma 
que, através deles, a vida penetra nela. Ao veicular concepções de mundo, a linguagem torna-se um lugar de confrontos ideológicos. $A$ palavra é o fenômeno ideológico por excelência, pois carrega uma carga de valores culturais que expressam as divergências de opiniões e as contradições da sociedade, tornando-se assim um palco de conflitos. Ela, no entanto, não pertence a ninguém, estando a serviço de qualquer ser humano e de qualquer juízo de valor.

Na realidade, não são palavras o que pronunciamos ou escutamos, mas verdades ou mentiras, coisas boas ou más, importantes ou triviais, agradáveis ou desagradáveis, etc. A palavra está sempre carregada de um conteúdo ou de um sentido ideológico ou vivencial. É assim que compreendemos as palavras e somente reagimos àquelas que despertam em nós ressonâncias ideológicas ou concernentes à vida. (BAKHTIN, 1929: 95).

O signo lingüístico tem, pois, uma plurivalência social que se refere ao seu valor contextual. $O$ fato de diferentes grupos sociais empregarem o mesmo sistema lingüístico faz com que as palavras manifestem valores ideológicos contraditórios, tendo o seu sentido firmado pelo contexto em que ocorrem. É a situação social imediata a responsável pelo sentido.

Outra característica do signo bakhtiniano, ligada à anterior, é a mutabilidade, uma vez que como reflexo das condições do meio social, a palavra é sensível às transformações na estrutura social, registrando todas as mudanças. As palavras estão presentes em todas as relações sociais e são tecidas a partir de uma infinidade de fios ideológicos, portanto serão sempre o indicador mais sensível de todas as transformações sociais (Bakhtin, ibid.: 41).

Inovando todos os estudos sobre a questão da pluralidade semântica das palavras nos discursos, Bakhtin $\left(1963^{4}: 263\right)$ analisou a vida da palavra, sua passagem de um locutor a outro, de um contexto a outro, de uma coletividade social, de uma geração a outra, e as via como unidade migratória entre discursos, sem 
desvincularem-se jamais de seu trajeto interdiscursivo e histórico anterior.

Ao produzirmos discursos, não somos a fonte deles, porém intermediários que dialogam e polemizam com os outros discursos existentes em nossa sociedade e em nossa cultura. Toda compreensão é um processo ativo e dialógico, portanto, tenso, uma vez que traz em seu cerne uma resposta, implicando sujeitos. $O$ processo compreensivo de um enunciado, segundo Bakhtin (1979), é sempre prenhe de respostas. O sujeito que produz um discurso não quer uma compreensão passiva, pois essa levaria à mera repetição de seu pensamento; ele almeja respostas que evidenciem adesão, concordância ou, contrariamente, objeção às idéias expostas.

Com esses argumentos, Bakhtin negava a coerência homogênea dos discursos, pois o tecido da memória discursiva é historicamente heterogêneo. A história intervém para possibilitar sentidos diversos, partindo de linearidades aparentes. É essa contradição que institui a alternância ou a simultaneidade de sentidos opostos, uma vez que, marcando a presença do outro que é plural, funda a diferença.

Ao retomar o pensamento bakhtiniano pelo viés da Análise de Discurso (AD), Maingueneau (1987: 115) salientou que essa "memória" não psicológica é presumida pelo enunciado enquanto inscrito na história, sendo constituída de seqüências que repetem, recusam e transformam outras seqüências, estabelecendo com elas uma relação polêmica. Dessa relação resultariam os efeitos de sentido, constituídos na relação histórica entre discursos.

A alteridade ou diferença é um fenômeno constitutivo de toda a linguagem, pois o é também do ser humano. Conforme Bakhtin,

O homem não possui território interior soberano, ele está inteiramente e sempre sobre uma fronteira; olhando o interior de si, ele olha nos olhos do outro ou através deles. [...] Não posso dispensá-lo, não posso tornar-me eu mesmo sem ele; devo encontrar-me nele, encontrando-o em mim (Bakhtin, 1961: 287). 
A identidade é, portanto, um movimento de reconhecimento em direção ao outro. Avançando na teoria enunciativa de Bakhtin, Maingueneau (1984) e Marandin (1993) aproximaram a memória discursiva do dizer - ou interdiscurso - das vozes dialógicas, considerando o primado de seu estudo dentro da AD. Seus estudos pregavam a definição da presença de discursos no interior do enunciado. O exterior constitutivo do interdiscurso teceria todos os discursos, tornando-os, assim, sempre habitados, ocupados pelas palavras dos outros. Reconhecer esse exterior seria dar uma identidade para o discurso.

História e memória fundem-se no interdiscurso, possibilitando efeitos semânticos variados. $A$ AD afirma que não se pode dizer tudo, no entanto, aquilo que não se disse permanece presente, produzindo efeitos, pois tem a ver com a memória histórica do dizer. A "negociação" que o sujeito trava com a palavra do outro é na verdade um "jogo" discursivo que construirá um dito, marcado pelo que não foi dito. Um dito marcado pela incompletude.

A incompletude também aparece como uma característica do discurso em e de Bakhtin. Brait (1994:16) fala em discurso inconcluso para definir a forma de enfrentamento com os outros discursos, passados ou presentes, que interagem na teoria bakhtiniana. Seu discurso (de Bakhtin), e sua idéia de discurso, manifesta um concerto de incessante produção de efeitos de sentido. O sentido é distribuído entre diversas vozes, em uma relação dialógica entre os diversos enunciados já produzidos sobre um mesmo tema. Resulta desse movimento um excesso impensado que é a própria possibilidade da pluralidade de sentidos.

A linguagem é incompleta no sentido de que tudo não se diz, mas o que não se diz continua presente, significando possibilidades. Era essa a interpretação de Bakhtin para o continuum infinito de sentidos inesgotáveis que, esquecidos, poderiam ser capturados pela memória histórica e discursiva e renovados em novos contextos.

O espaço da subjetividade na linguagem é um espaço tenso. O processo interativo da enunciação evidencia essa tensão constante que constitui os sujeitos e os sentidos, pois há sujeitosvozes e sentidos em conflito na memória discursiva. 
Estabelece-se o conflito porque há um pensamento já existente, anterior ao sujeito e que não coincide completamente com - que ele produz ou interpreta no momento presente. Esse pensamento-outro tem um conteúdo impensado, que deixa o sentido inconcluso, incompleto. Tal conteúdo de sentidos esquecidos pode ser resgatado e reorganizado, provocando um acontecimento discursivo, ou em outros termos, um sentido inédito.

Vamos nos deter um momento nesse impensado que constitui o sentido e efetuar, novamente, um exercício filosófico de pensamento, convocando para a discussão Merleau-Ponty (1960), que definia o impensado como excesso, uma outra coisa além da existência dada. Ou, nas palavras de Chauí (1983), uma positividade negativa por conter, contraditoriamente, um elemento de negação que provoca um porvir possível.

O impensado não é o "menos" ou o que não foi pensado, mas o "excesso" do que se quis dizer e do que foi dito. O impensado é o que ressalta 0 inerente a todo o pensamento, mesmo não estando visível formalmente. Não é senão o excesso do que vivemos sobre o que já foi dito. (Merleau-Ponty, 1960: 175).

Não é o que estaria ausente como privação, mas aquilo cuja ausência é promessa e antecipação. Como todo invisível, o impensado é uma ausência que conta no mundo porque não é um vazio, mas ponto de passagem. Não é buraco. É poro. (Chauí, 1983: 206).

O impensado é um ponto de passagem para um sentido que é possível, mas ainda não se encontra presente. É, portanto, possibilidade plural de sentidos.

Essa dimensão "impensada" do sentido está estreitamente vinculada à sua incompletude e, por oposição, à sua sedimentação, na mesma perspectiva sustentada por Bakhtin de uma interpretação jamais ser a final. Há leituras e interpretações múltiplas que impossibilitam o fechamento do discurso como representação acabada.

Merleau-Ponty (ibid.) afirmava que a idéia do sentido fixo seria conseqüência da ilusão da coincidência entre a linguagem e o 
que ela representa. A idéia de uma expressão completa ou acabada é um non-sense, uma vez que a linguagem é sempre indireta, alusiva, portanto, opaca, o que impede a cristalização do sentido. Dizer não é colocar uma palavra sob (ou sobre) cada coisa pensada: se assim o fizéssemos nada seria jamais dito. (...) A linguagem significa quando, em vez de copiar o pensamento, deixa-se por ele desfazer e refazer. (Merleau-Ponty, 1960: 145).

Esse desfazer e refazer da linguagem reflete o que para a AD, conforme Orlandi (1996), é a capacidade de jogar com a língua que, inscrita na história, possibilita a construção de sentidos. Sentidos possíveis, porém não quaisquer, visto que a materialidade da língua impede-lhe isso.

Há no discurso uma possibilidade de resistência a dizer o mesmo que rompe com a regra. O sistema da língua permite um jogo de subversão da norma. Existe uma latitude de jogo que a afeta e que permite trapacear a língua, surpreender a linguagem, como disse Barthes (1978). Todo o movimento de ruptura com a ordem lingüística, no entanto, deve implicar uma recusa à concepção da linguagem como mero instrumento de informação, pois essa idéia estabelece-se sob o primado da norma e do consenso social.

Ora, todo enunciado pode tornar-se outro, deslocar-se de seu sentido e derivar para um outro. Pêcheux (1983) já alertara para isso e, antes dele Bakhtin (1929) ao postular a dialética do signo mutável, sua eterna possibilidade de vir a ser em oposição à tendência de estabilização semântica que ocorre por essa fiç̧ão de imaginar a palavra como um decalque da realidade. Não existe unicidade no sentido, senão fecundidade. Há tantos sentidos possíveis quanto contextos e esses contextos de uma mesma expressão são freqüentemente opostos. Os contextos estão ligados à situação social e histórica. Reproduzem-se e atualizam-se as unidades da língua, mas as instâncias discursivas são únicas.

Após termos delineado os aspectos teóricos que orientam nossa discussão à cerca da identidade e da diferença, gostaríamos de propor alguns exemplos, retirados dos discursos do cotidiano, a fim de ilustrar, na prática, o que acontece a respeito do assunto.

Partiremos do questionamento dos sentidos de determinadas palavras em discursos específicos, apontando a plurivalência semântica que as constitui, ao integrarem contextos 
diversos. Nosso primeiro exemplo, permanecendo no campo dos estudos de gênero, comparará interpretações possíveis das palavras feminina e feminista.

Como observamos acima, na França dos anos 70, cientistas sociais e militantes dos estudos sobre a mulher posicionaram-se de acordo com sua postura política: a favor do termo feminista, os seguidores das tendências socialistas e marxistas; enquanto seus opositores, seguindo orientações ligadas aos estudos psicanalíticos, advogaram pelo vocábulo feminino. Entretanto, políticas à parte, o uso de um ou de outro poderia derivar para a sinonímia.

O senso comum, geralmente, mostra-se mais complacente com o segundo (feminino), uma vez que o outro tem sido interpretado, ao longo das últimas décadas, como um sinônimo para queimadoras de soutiens. Por outro lado, os adeptos da palavra feminista rechaçam a outra por sua significação estereotipada, ligada à passividade e submissão.

Observemos o que nos diz o dicionário Aurélio a esse respeito: feminino caracteriza a relação biológica com ovário, enquanto feminista remete a feminismo, substantivo com forte conotação política, que refere à equiparação dos direitos das mulheres aos dos homens. À primeira vista, podemos interpretar as classificações como adendos ao senso comum, ou seja, existe uma essência feminina, ligada ao sexo biológico, que não tem a ver com as manifestações políticas referentes ao adjetivo feminista.

Da mesma forma, teremos opiniões diversas, confirmando o senso comum, se indagarmos a respeito da significação das expressões ser feminista e ser feminina. A maioria das mulheres afirma não ser feminista, porém feminina, devido ao valor semântico negativo atrelado à primeira expressão.

Em trabalho anterior (Pires, 1992: 46), discutimos a carga ideológica de certas palavras que carregam valores positivos ou negativos, dependendo do comportamento mais, ou menos, conservador da sociedade que as emprega. Progresso, democracia, liberdade, consciência, já foram justificativas tanto para libertar como para oprimir sociedades. Outras, como liberal ou radical podem ser consideradas tanto um elogio quanto uma ofensa, dependendo de seu uso contextual. Um liberal pode indicar um libertário ou um reformista conciliador, partidário do liberalismo político. Já radical 
pode evocar um extremista desprovido de bom senso ou alguém que vai ao cerne dos problemas.

No domínio político, a plurivalência semântica é muito flagrante. Os signos lingüísticos variam de significado de um país para outro e dependendo de épocas, como variam, também, de geração a geração e de um grupo para outro dentro de um mesmo país, chegando muitas vezes a criarem dúvidas ou constrangimento de quem as escuta na boca de certas pessoas.

O poeta Thiago de Mello (1984:25) expressa esse sentimento em um de seus poemas, com referência a termos como reforma agrária, justiça social, socialismo, liberdade,

Mas as palavras de brasa, as terríveis palavras perseguidas, pelas quais nos amarraram a boca, hoje entram em todas as casas, proferidas a cores, pelos antigos mordaceiros da luz, mas lavadas por dentro, esvaziadas de tudo o que nelas era poder de pássaro e canção.

Voltando ao âmbito das relações de gênero, referimos o interessante estudo de Coulthard (1991) à cerca da linguagem vinculada ao sexo. $O$ autor atesta existir no emprego de algumas expressões, um significado positivo, quando relacionadas ao sexo masculino; ao mesmo tempo, em relação ao sexo feminino, as mesmas palavras conotariam um sentido negativo. Trata-se das metáforas zoomórficas, empregadas para engrandecer o homem ou menosprezar a mulher, remetendo à herança do bipolarismo sexista. Coulthard distinguiu, entre outros, os substantivos cavalo e touro em oposição à égua e vaca. Podemos acrescentar outros como cobra ou galo/galinha.

A bem da verdade, há algum tempo ocorrem mudanças nesse terreno, atestando uma visão mais equânime, que decorrem, principalmente, de setores mais jovens e evoluídos. É o caso dos substantivos gato e gata, considerados sinônimos de beleza para ambos os sexos. 
O que dissemos nos parágrafos precedentes demonstra, também, a mutabilidade do signo lingüístico, conforme pregou Bakhtin (1929), já que esse reflete as transformações sociais. Reforçando o tema, e como último exemplo, consideremos o conteúdo nocional da palavra divórcio e do sintagma ser divorciado ao longo dos últimos vinte anos. Em $1977^{5}$, quando foi aprovado o projeto que instituiu o divórcio no Brasil, ainda era um verdadeiro tabu ser desquitada/o, a ponto de, principalmente as mulheres, sofrerem um tipo de segregação social. Foram necessários muitos anos para a mudança de sentido dos termos. Sua significação alterou-se devido às circunstâncias, à propaganda $e$ às transformações sociais em torno da matéria, a ponto de, atualmente, terem desaparecido as discriminações relativas à questão.

Concluindo este trabalho, diremos que a realidade sempre nos oferece alternativas de vida, particularmente em relação à aceitação ou recusa do mundo social em que vivemos. Em nossa época, temos a oportunidade de tentar retificar as desigualdades, estabelecidas pela ênfase em naturalizar as relações sociais e enaltecer as diferenças. Devemos fazê-lo, reconhecendo as diferenças não apenas entre homens e mulheres, mas entre as próprias mulheres, sem, entretanto, deixar de enfatizar que tanto as diferenças quanto o que temos em comum constroem a nossa identidade. Sem esquecermos a tensão sempre existente entre nossa liberdade $e$ as condições sociais (naturais, culturais, psíquicas) que nos determinam.

Ocorre o mesmo em relação a nossa produção discursiva: os sentidos inéditos sempre se ancoram nos já instituídos. A partir dessa ancoragem, realizam-se os deslizes que instauram o sentidooutro. Advém, assim, um confronto discursivo, cujo jogo lingüísticosemântico pode causar surpresas. Ou não. Uma análise imediata enfatizará o mesmo, facilitando um efeito aparente de evidência. Conquanto nos detenhamos um pouco mais, perceberemos como a linguagem pode, pelo fato de ser oblíqua, provocar uma fecundidade de sentidos. Na verdade, todos eles já se encontram lá, significando, mesmo os que não foram ditos. 


\section{NOTAS}

${ }^{1}$ Em todas as citações, trabalharemos com a data da publicação original.

2 Para uma visão geral das diferentes correntes das teorias de gênero e suas pesquisas até meados dos 80 , ver o interessante trabalho de J. Scott, publicado em 1986, Gênero: uma categoria útil de análise histórica.

${ }_{3}$ As referências concentram-se nos textos: 0 problema dos gêneros do discurso, originais de 1952/53 e 0 problema do texto nas áreas da lingüística, da filologia, das ciências humanas. Tentativa de uma análise filosófica, originais de 1959/61.

${ }^{4}$ Trabalhamos com a edição modificada da original de 1929, em sua tradução para o inglês.

${ }^{5} \mathrm{O}$ assunto era tão polêmico que a lei regulamentando o divórcio somente foi sancionada em 1989.

\section{REFERÊNCIAS BIBLIOGRÁFICAS}

BAKHTIN, M. (VOLOCHÍNOV). (1929) Marxismo e filosofia da linguagem. 3. ed. São Paulo: Hucitec, 1986.

. (1961) Towards a reworking of the Dostoievsky book. In: Problems of Dostoievsky's poetics. (1963) 3. ed. Minneapolis: University of Minnesota Press, 1987.

(1963). Problems of Dostoievsky's poetics. 3. ed. Minneapolis: University of Minnesota Press, 1987.

. (1979) Estética da criação verbal. 2. ed. São Paulo: Martins Fontes, 1997.

BARTHES, R. (1978) Aula. São Paulo: Cultrix, s.d.

BEAUVOIR, S. (1949) O segundo sexo. 3. ed. Rio de Janeiro: Nova Fronteira, 1981. 2 volumes.

BRAIT, B. As vozes bakhtinianas e o diálogo inconcluso. In: PESSOA DE BARROS, D.; FIORIN, J.L. (org.) Dialogismo, polifonia, intertextualidade. São Paulo: Edusp, 1994.

CERTEAU, M. de. (1974) A cultura no plural. Campinas: Papirus, 1995. 
CHAUÍ, M.S. Da realidade sem mistérios ao mistério do mundo: Espinosa, Voltaire, Merleau-Ponty. 3. ed. São Paulo: Brasiliense, 1983.

COULTHARD, M. Linguagem e sexo. São Paulo: Ática, 1991.

DESCOMBES, V. (1979) Lo mismo y lo otro. 2. ed. Madri: Ediciones Cátedra S. A., 1988.

DUBY, G.; PERROT, M. (1993) As mulheres e a história. Lisboa: Publicações Dom Quixote, 1995.

FERREIRA, A. B. de $\mathrm{H}$. Novo dicionário da língua portuguesa. Rio de Janeiro: Nova Fronteira, 1975.

FLAX, J. (1990) Pós-modernismo e relações de gênero na teoria feminista. In: HOLLANDA, H. B. (org.) Pós-modernismo e política. Rio de Janeiro: Rocco, 1992.

MACHADO, L. Z. Estudos de gênero: para além do jogo entre intelectuais e feministas. In: SCHPUN, M. R. Gênero sem fronteiras. Florianópolis: Editora Mulheres, 1997.

MAINGUENEAU, D. Genèses du discours. Bruxelas: Pierre Mardaga, 1984.

. (1987) Novas tendências em análise do discurso. Campinas: Pontes e Ed. da Unicamp, 1989.

MARANDIN, J.-M. (1993) Sintaxe, discurso: do ponto de vista da análise do discurso. In: ORLANDI, E. P. (org.) Gestos de leitura: da história no discurso. Campinas: Ed. da Unicamp, 1994.

MELLO, T. de. Mormaço na floresta. São Paulo: Círculo do Livro, 1984.

MERLEAU-PONTY, M. (1960) A linguagem indireta e as vozes do silêncio. In: Os Pensadores. São Paulo: Abril Cultural, 1980.

ORLANDI, E. P. Interpretação: autoria, leitura e efeitos do trabalho simbólico. Petrópolis: Vozes, 1996.

PÊCHEUX, M. (1983) O discurso: estrutura ou acontecimento. Campinas: Pontes, 1990.

PIRES, V. L. Ideologia e discurso pedagógico: o papel do professor na produção de um discurso polêmico. Dissertação de mestrado. Santa Maria: UFSM, 1992.

RUBIN, G. The traffic in women: notes on the political economy of sex. In: REITER, R. R. (ed.) Toward an Anthropology of Women. New York: Monthly Review Press, 1975. 
SCOTT, J. (1986) Gênero: uma categoria útil de análise histórica. Revista Educação e Realidade. Porto Alegre: Ed. da UFRGS. V. 20, no 2, 1995. p.71-99.

ZARETSKY, E. Social Theory and the Politics of Identity. London, Blackwell, 1994. 


\section{SOBRE A AUTORA}

Vera Lúcia Pires é licenciada em Letras pela UFRGS. Obteve o grau de Mestre em Educação pela UFSM e o de Doutor em Lingüística pela PUCRS. Leciona Língua Alemã e Estudos Lingüísticos nos cursos de Graduação e Pós-Graduação em Letras e Psicologia; e Teorias Lingüísticas e Teorias da Enunciação no Pós-Graduação em Letras da UFSM. Orienta pesquisas na área de Discurso e Enunciação e integra o Laboratório Corpus e o GRPESQ/ CNPq Discurso, História, Gênero e Identidade. É autora de diversos artigos em livros e revistas da área de estudos lingüísticos. 


\section{NÚMEROS DISPONÍVEIS}

Fragmentum é uma publicação do Laboratório Corpus. A primeira série de artigos será constituída de textos apresentados no II Seminário Corpus. Os três eixos temáticos discutidos são a memória, a história e a identidade.

A publicação é distribuída gratuitamente aos participantes do Laboratório Corpus durante os Seminários de Trabalho que ocorrem mensalmente no Centro de Educação, Letras e Biologia.

Eis os números disponíveis:

Fragmentum 1

História, memória e mito no Romanceiro da Inconfidência

Sílvia Carneiro Lobato Paraense

Fragmentum 2

Memória da escrita e escrita da memória

Marcia Cristina Corrêa

Fragmentum 3

Questões sobre identidade e diferença:

tensão entre o mesmo e o outro

Vera Lúcia Pires

A fim de obter maiores informações, entre em contato com Mirian de Paula, através do e-mail: mibrum@uol.com.br. 